\title{
The Voice Enabled Personal Assistant for Pc using Python
}

\author{
V. Geetha, C.K.Gomathy, Kottamasu Manasa Sri Vardhan, Nukala Pavan Kumar
}

\begin{abstract}
Personal Assistants, or conversational interfaces, or chat bots reinvent a new way for individuals to interact with computes. A Personal Virtual Assistant allows a user to simply ask questions in the same manner that they would address a human, and are even capable of doing some basic tasks like opening apps, reading out news, taking notes etc., with just a voice command. Personal Assistants like Google Assistant, Alexa, Siri works by Speech Recognition (Speech-to-text) and Text-to-Speech.

Keywords: Personal Assistants; chat bots; conversational interfaces; Speech Recognition; Text-to-Speech.
\end{abstract}

\section{INTRODUCTION}

$\mathrm{K}_{\mathrm{n}}$ become an integral part of our lives these days. It is because of all the features and ease of use they provide. Personal Assistants are also capable of automating some day-to-day tasks, so that a user can focus on what matters the most to them. Features like, making calls, writing messages, taking photographs, storing to-dos on the go, browsing internet etc., are offered by personal assistants. So, utilization of these features of a virtual assistant will save an individual a lot of time, and effort. It is important to focus more on what matters the most for an individual, whether it could be personal work, or professional work. People often spend more time on doing routine tasks, and they can be automated with these types of personal assistants. When someone works in an environment with which he/she is not familiar with, they often find it difficult to locate applications that they need, like browser, any IDE or nay other software. Most of the time, they will end up wasting hours of time, searching for the application alone. This results in unnecessary time wastage. Therefore, a voice enabled personal assistant will help automating this process. User is expected just to give a voice command, and the assistant will take care of the rest.

Manuscript received on April 07, 2021.

Revised Manuscript received on April 12, 2021.

Manuscript published on April 30, 2021.

* Correspondence Author

Dr. V. Geetha, Assistant Professor, CSE Department, SCSVMV Deemed to be University, Kanchipuram, Tamil Nadu.

Dr. C K Gomathy*, Assistant Professor, CSE Department, SCSVMV Deemed to be University, Kanchipuram, Tamil Nadu.

Mr. Kottamasu Manasa Sri Vardhan, UG Scholar CSE Department, SCSVMV Deemed to be University, Kanchipuram, Tamil Nadu.

Mr. Nukala Pavan Kumar, UG Scholar CSE Department, SCSVMV Deemed to be University, Kanchipuram, Tamil Nadu.

(c) The Authors. Published by Blue Eyes Intelligence Engineering and Sciences Publication (BEIESP). This is an open access article under the CC BY-NC-ND license (http://creativecommons.org/licenses/by-nc-nd/4.0/)
The paper indicates the usage of a Voice enabled personal assistant and it can enable an individual to get things done with voice commands, and can save a lot of their time as well. This Voice enabled personal assistant can be implemented by using technologies like Speech-to-Text and Text-to-Speech, and can be integrated with other functionalities as well, depending on our requirement.

\section{LITERATURE SURVEY}

Personal Assistants, or Virtual assistants have become an integral part of our lives these days. Every organisation, or individual is switching to this kind of technologies, as they help them get their things done in an easier way.

This system is based on a Desktop Application. This system includes a Virtual Assistant, that is capable of accepting input from the user, understanding it, analysing it, and performing tasks accordingly. This helps users save a lot of time.

\section{PROPOSED METHODOLOGY}

In this proposed concept effective way of implementing a Personal voice assistant, Speech Recognition library has many in-built functions, that will let the assistant understand the command given by user and the response will be sent back to user in voice, with Text to Speech functions. When assistant captures the voice command given by user, the under lying algorithms will convert the voice into text. And according to the keywords present in the text (command given by user), respective action will be performed by the assistant. This is made possible with the functions present in different libraries. Also, the assistant was able to achieve all the functionalities with help of some API's. We had used these APIs for functionalities like performing calculations, extracting news from web sources, and for some other things. We will be sending a request, and through the API, we're getting the respective output. API's like WOLFRAMALPHA, are very helpful in performing things like calculations, making small web searches. And for getting the data from web, not every API will have the capability to convert the raw JSON data into text. So, we used a library called JSON, and it will help in parsing the JSON Data coming form websites, to string format. In this way, we are able to extract news from the web sources, and send them as input to a function for further purposes. Also, we have libraries like Random and many other libraries, each corresponding to a different technology. We used the library OS to implement

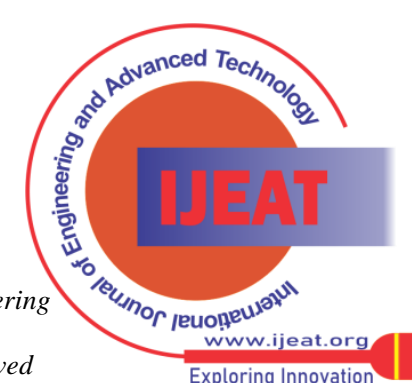

Eubes Intelligence Engineering

\& Sciences Publication 


\section{The Voice Enabled Personal Assistant for Pc using Python}

Operating System related functionalities like Shutting down a system, or restarting a system. pyautogui is a library that is implemented for functionalities like, capturing a screenshot. psutil is a library, and is used for functionalities like checking battery status.

\section{TECHNOLOGIES USED}

The programming language used in this project is Python, which is known for its versatility, and availability of wide range of libraries. For programming the Virtual Assistant, we used Microsoft Visual Studio Code (IDE) which supports Python programming language. Speech Recognition library is present in Python, and is having some in-built functions. Initially, we will define a function for converting the text to speech. For that, we use pyttsx3 library. We will initialize the library instance to a variable. We use say() method and pass the text as an argument to that, for which the output will be a voice reply. For recognizing the voice command given by user, another function has been defined. In that function, define microscope source and within its scope, we use respective functions and store the output in a variable. For the whole process, we have many services to use, like Google Speech Recognition engine, Microsoft Bing Voice Recognition engine, and products of many other big companies like IBM, Houndify etc., For this project, we choose Google's Speech Recognition Engine, that will convert the respective analog voice command into a digital text format. We pass that text as an input to the Assistant, and it will search for the keyword. If the input command has a word that matches with the respective word, the respective function will be called, and it will perform the action accordingly, like telling time, or date, or telling battery status, taking a screenshot, saving a short note, and many more.For this Personal Virtual Assistant, the main advantage is that it saves a lot of time, and it can even handle queries from people, of different voices. There is no rule that one has to give any exact specified command to trigger a particular action. User has the flexibility to give command for user, in natural language. The programming language used to design this Voice enabled Personal Assistant for PC is PYTHON 3.8.3. And the IDE (Integrated Development Environment) that we used is Microsoft Visual Code.

\section{SYSTEM ARCHITECTURE}

This Assistant consists of three modules. First is, assistant accepting voice input from user. Secondly, analysing the input given by the user, and mapping it to the respective intent and function. And the third is, the assistant giving user the result all along with voice.

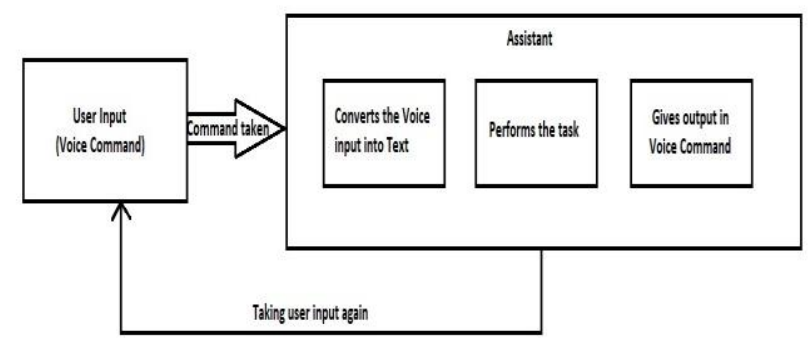

Fig 1: Block Diagram
Initially, the assistant will start accepting the user input. After receiving the input, the assistant will convert the analog voice input to the digital text. If assistant was not able to convert the voice into text, it will start asking user for the input again. If converted, it will start analyzing the input and will map the input with particular function. And later, the output will be given to user via the voice command.

\section{WORKING MODEL}

The assistant, on starting, will initially wait for the input to be given from user. If the user gives input command, via voice, the assistant will capture it, and searches for the keyword present in the input command. If the assistant was able to find a key word, then it will perform the task accordingly, and returns the output back to user, in voice. If not, the assistant will again start waiting for the user to give input.Each of these functionalities are having their own importance in the whole system working.

- User Input-The assistant will wait for the user to give voice command for further processing.

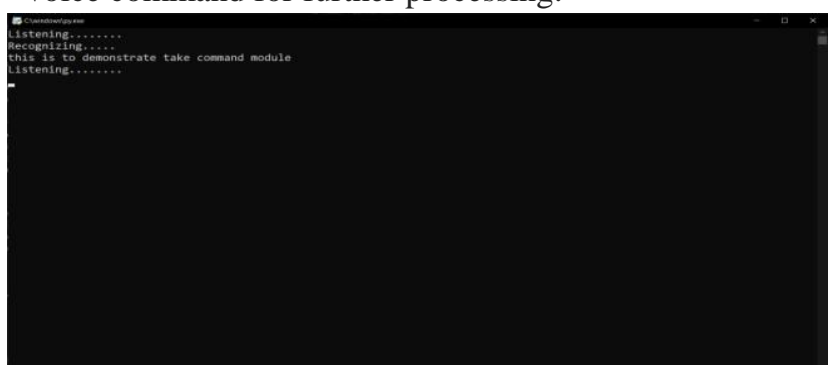

Fig 2: User Input

- Introducing to user-The user who is asking assistant to introduce itself, will display the following.

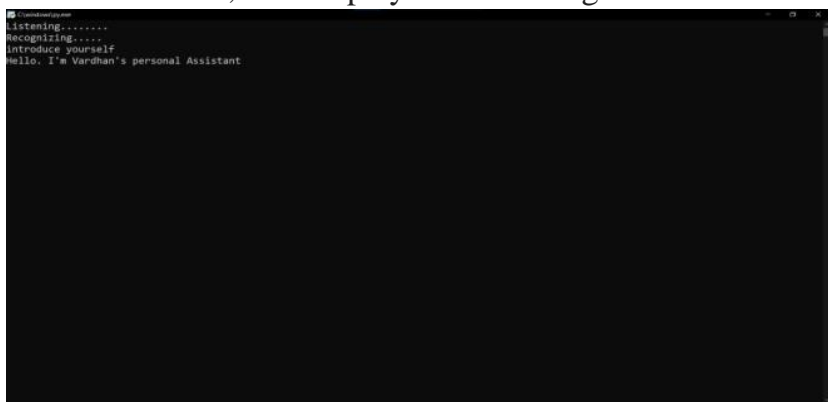

Fig 3: Introducing itself

- $\quad$ Reading out news - If the user asks the assistant to read out some news, the assistant will display the new line by line and it will also read out the news.

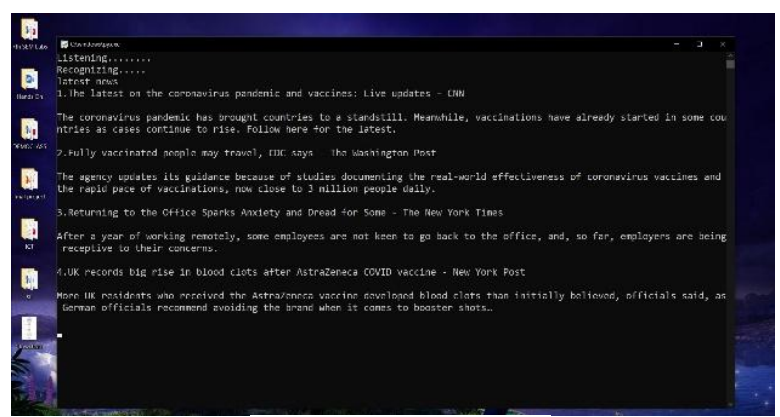

Fig 4: Reading news

Published By:

Blue Eyes Intelligence Engineering DOI:10.35940/ijeat.D2425.041042

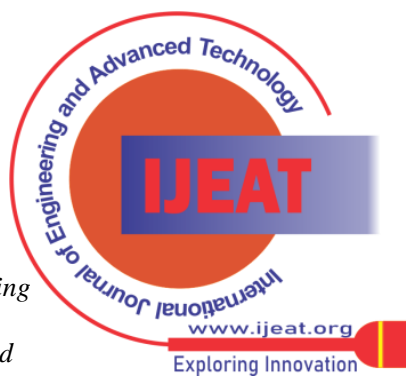


- Taking a sample note-If the user has a small note to be taken, he can ask the assistant to do so, and the assistant will take the notes and save it in a notepad file.

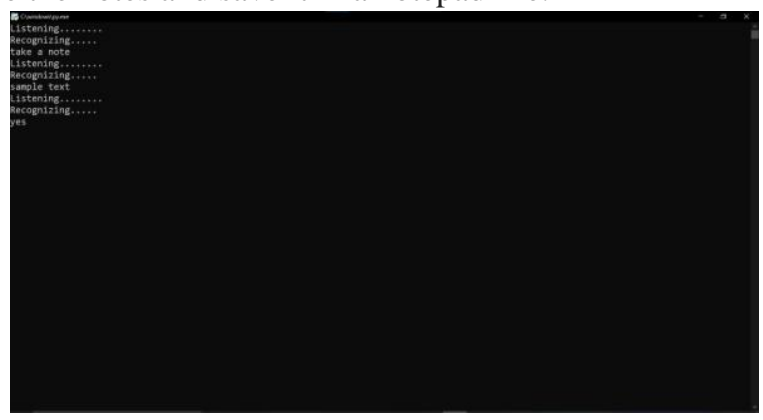

Fig 5: Taking a short note

- Showing Note-If the user asks the assistant to display the note, and to speak out the note, the assistant will do so.

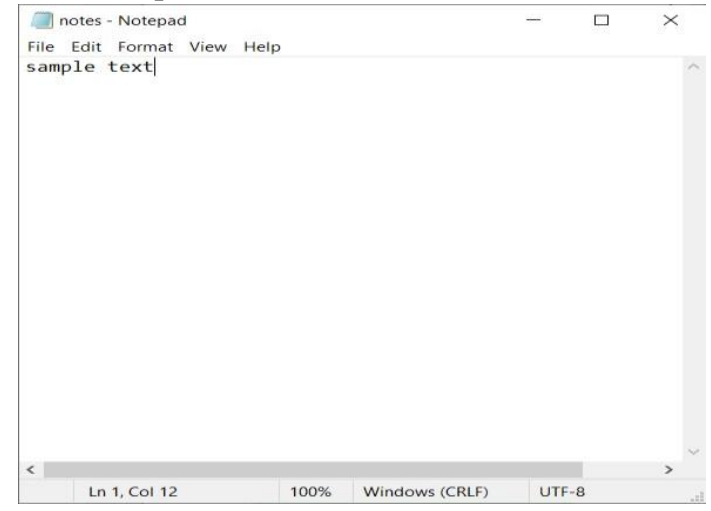

Fig 6: Notes, saved in a notepad file

- YouTube searches-If the user asks the assistant to do some YouTube searches, the assistant will do that. It will ask the user, what to search in YouTube. After receiving the input, it will open the YouTube page with that respective search.

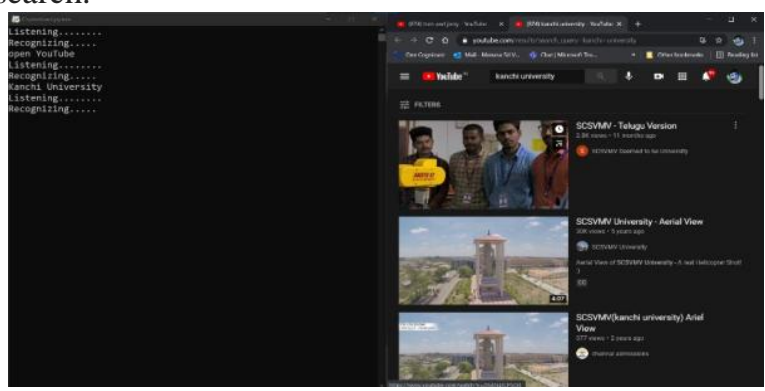

Fig 7: Asking assistant to open YouTube

- Web Searches-If the user asks the assistant to do some web searches, the assistant will also do that. It will ask the user to search for what, and it will open the google search in a new tab of browser.

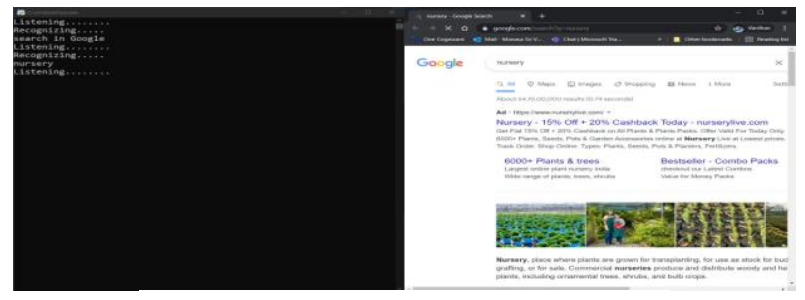

Fig 8: Assistant doing google search

- Opening Applications - If the user asks the assistant to open an application, like MS Word, or any other, the assistant will do so immediately. And also, it will speak that it opens the application.

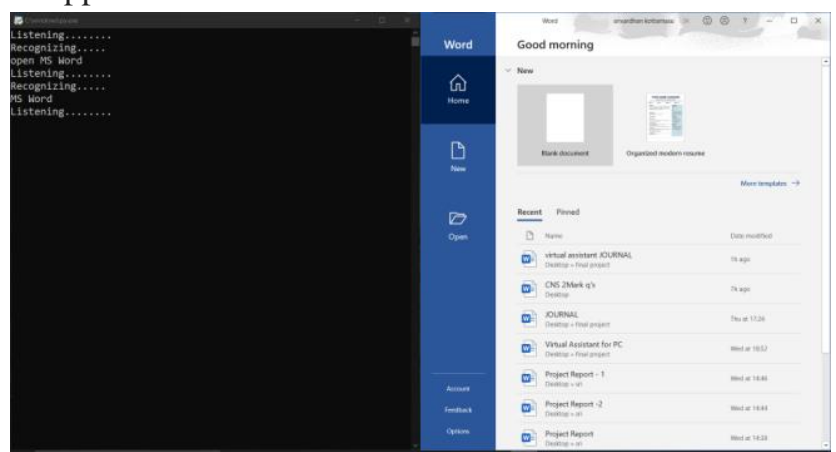

Fig 9: Assistant opening MS Word

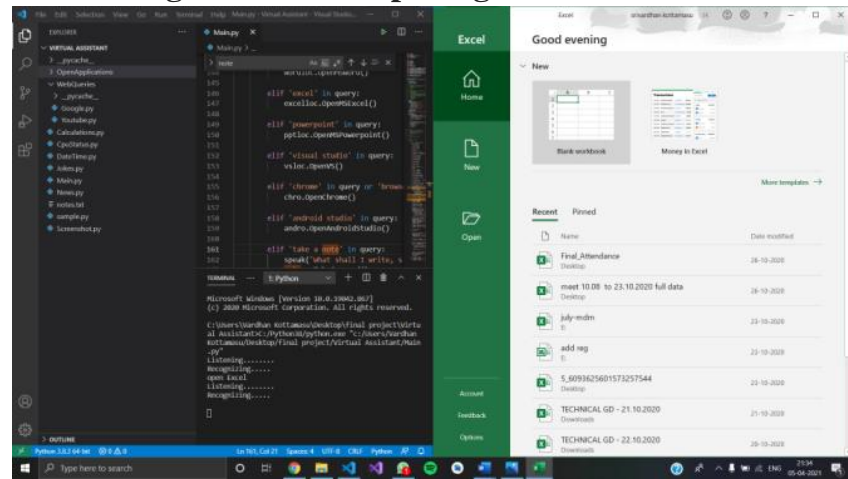

Fig 10: Assistant opening MS Excel

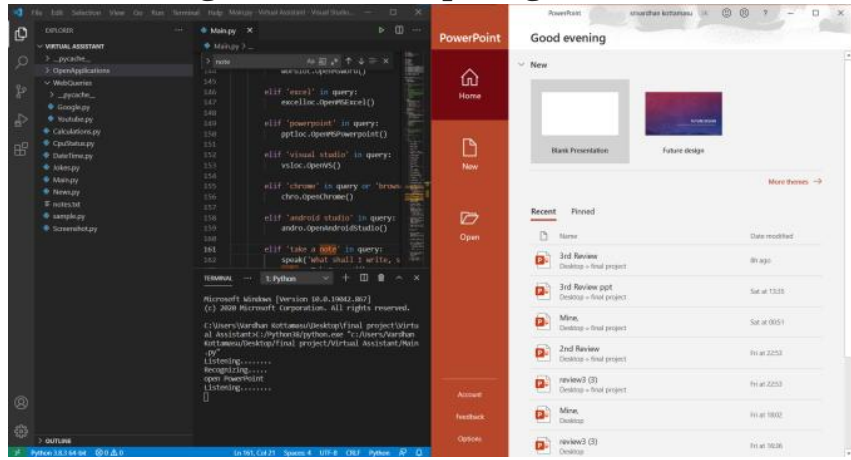

Fig 11: Assistant opening MS Power point

- Performing Calculations-If the user asks the assistant to do some calculations, the assistant will speak out the result

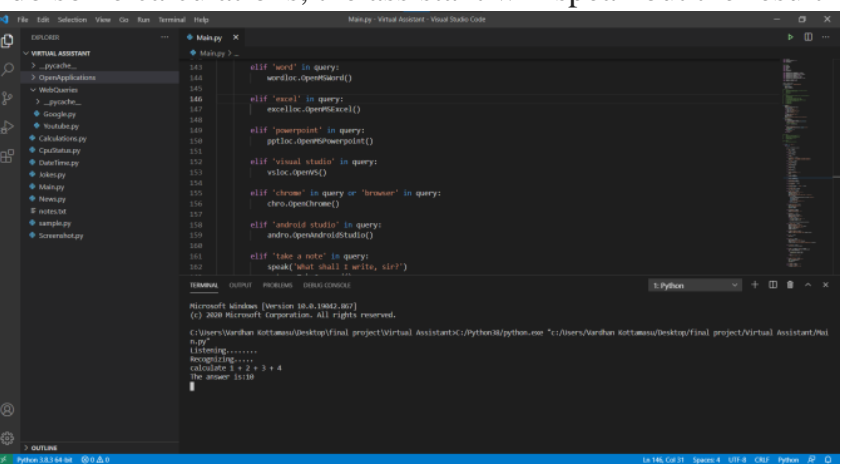

Fig 12: Assistant doing calculations

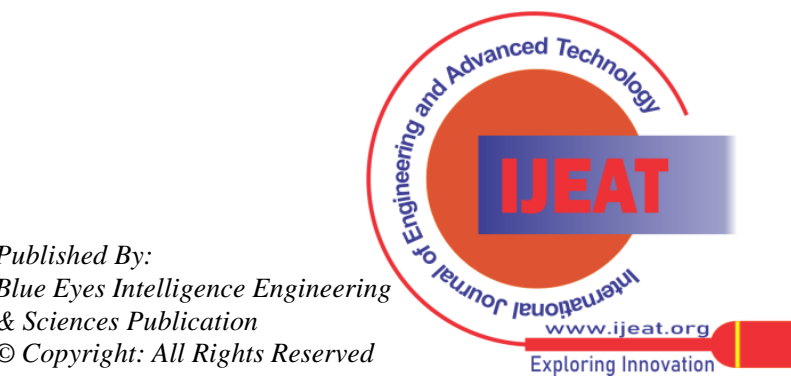




\section{The Voice Enabled Personal Assistant for Pc using Python}

- Taking Screenshots - If the user asks the assistant to take screenshots, the assistant will take a screenshot, and will save it in a particular location.

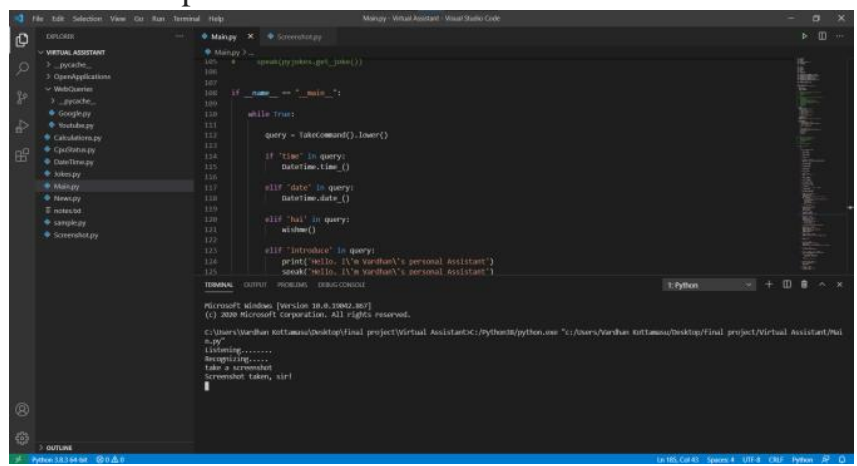

Fig 13: Assistant taking a screenshot

- Locating a place-If the user asks the assistant to locate a place, the assistant will open the Google Map with that location

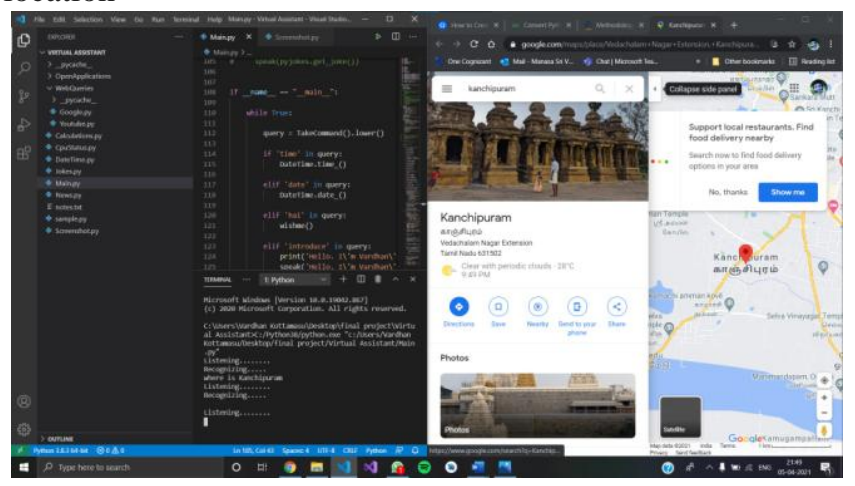

Fig 14: Assistant locating a place in Google Maps

\section{CONCLUSION}

This paper presents a comprehensive overview of the design and development of a Voice enabled personal assistant for pc using Python programming language. This Voice enabled personal assistant, in today's life style will be more effective in case of saving time, compared to that of previous days. This Personal Assistant has been designed with ease of use as the main feature. The Assistant works properly to perform some tasks given by user. Furthermore, there are many things that this assistant is capable of doing, like turning our PC off, or restarting it, or reciting some latest news, with just one voice command.

\section{REFERENCES}

1. Elizabeth Sucupira Furtado, Virgilio Almedia And Vasco Furtado, "Personal Digital Assistants: The Need Of Governance"

2. Zecheng Zhan, Virgilio Almedia, And Meina Song, "Table-To-Dialog: Building Dialog Assistants To Chat With People On Behalf Of You"

3. Yusuf Ugurlu, Murat Karabulut, Islam Mayda "A Smart Virtual Assistant Answering Questions About COVID-19" Mathangi Sri "NLP In Virtual Assistants"

4. Anxo Pérez, Paula Lopez-Otero, Javier Parapar. "Designing An Open-Source Virtual Assistant"

5. C K Gomathy And V Geetha. Article: A Real Time Analysis Of Service Based Using Mobile Phone Controlled Vehicle Using DTMF For Accident Prevention. International Journal Of Computer Applications 138(2):11-13, March 2016. Published By Foundation Of Computer Science (FCS), NY, USA,ISSN No: 0975-8887

6. Dr.C.K.Gomathy , K. Bindhu Sravya , P. Swetha , S.Chandrika Article: A Location Based Value Prediction For Quality Of Web
Service, Published By International Journal Of Advanced Engineering Research And Science (IJAERS), Vol-3, Issue-4 , April- 2016] ISSN: 2349-6495

7. $\quad$ C.K.Gomathy And Dr.S.Rajalakshmi.(2014),"A Business Intelligence Network Design For Service Oriented Architecture", International Journal Of Engineering Trends And Technology (IJETT), Volume IX, Issue III, March 2014, P.No:151-154, ISSN:2231-5381.

8. "Virtual Personal Assistant (VPA) For Mobile Users"

9. D. SOMEShWAR, DHARMiK BHANUShali, SWATI NADKARNI, "IMPLEMENTATION OF ViRTUAL AsSistant With Sign LANGUAGE USING DEEP LEARNING AND TENSORFLOW"

10. C.K.Gomathy.(2010),"Cloud Computing: Business Management For Effective Service Oriented Architecture" International Journal O Power Control Signal And Computation (IJPCSC), Volume 1, Issue IV, Oct - Dec 2010, P.No:22-27, ISSN: 0976-268X.

11. Dr.C K Gomathy, Article: A Semantic Quality Of Web Service Information Retrieval Techniques Using Bin Rank, International Journal Of Scientific Research In Computer Science Engineering And Information Technology ( IJSRCSEIT ) Volume 3 | Issue 1 | ISSN : 2456-3307, P.No:1563-1578, February-2018

12. Dr.C K Gomathy, Article: A Scheme Of ADHOC Communication Using Mobile Device Networks, International Journal Of Emerging Technologies And Innovative Research ( JETIR ) Volume 5 | Issue 11 ISSN : 2349-5162, P.No:320-326, Nov-2018.

13. Dr.C K Gomathy, Article: Supply Chain-Impact Of Importance And Technology In Software Release Management, International Journal Of Scientific Research In Computer Science Engineering And Information Technology ( IJSRCSEIT ) Volume 3 | Issue 6 | ISSN : 2456-3307, P.No:1-4, July-2018

14. Hemalatha. C.Kand N. Ahmed Nisar (2011)., Explored Teachers' Commitment In Self Financing Engineering Colleges, International Journal Of Enterprise Innovation Management Studies (IJEIMS), Vol2. No2. July-Dec 2011 ISSN: 0976-2698 Retrieved From Www.Ijcns.Com

15. Dr.C K Gomathy, Article: The Efficient Automatic Water Control Level Management Using Ultrasonic Sensor, International Journal Of Computer Applications (0975 - 8887) Volume 176 - No. 39, July 2020.

16. C K Gomathy And V Geetha. Article: A Real Time Analysis Of Service Based Using Mobile Phone Controlled Vehicle Using DTMF For Accident Prevention. International Journal Of Computer Applications 138(2):11-13, March 2016. Published By Foundation O Computer Science (FCS), NY, USA,ISSN No: 0975-8887

\section{AUTHORS PROFILE}

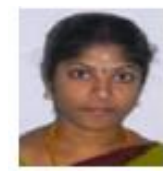

Dr.V.Geetha, is assistant professor in computer science and engineering at Sri Chandrasekharendra Saraswathi Viswa Mahavidyalaya , Enathur,Kanchipuram,India. Her area of intrest lies in Java Programming,Software Quality Assurance,Computer System Architecture Domain.

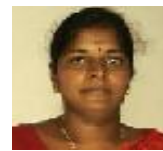

Dr C,K,Gomathy, is Assistant Professor in CSE at Sr Chandrashekarendra Saraswathi Viswa Mahavidyalaya deemed to be university, Enathur, Kanchipuram, India. Her area of Intrest is Software Engineering Web Services, Knowledge Management and IOT.

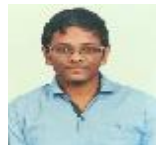

Kottamasu Manasa Sri Vardhan, student, B.E Computer Science and Engineering, SCSVMV Deemed to be university,Enathur.

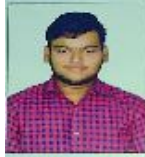

Nukala Pavan Kumar, student, B.E. Computer Science and Engineering, SCSVMV Deemed to be university,,Enathur.

Published By:

Blue Eyes Intelligence Engineering

\& Sciences Publication

(C) Copyright: All Rights Reserved

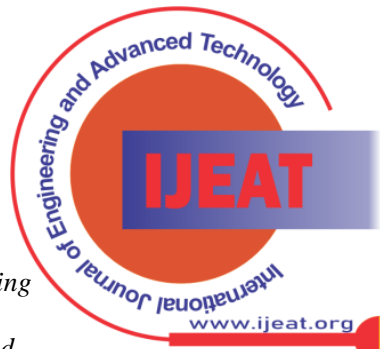
Exploring Innovation 